\section{El Apego}

Rene Spitz en 1950, ya observó que los niños en condiciones de privación materna experimentaban angustia y corrían el riesgo de desarrollar psicopatología. Posteriormente Bowlby, señala la poderosa influencia de las relaciones tempranas de apego en el desarrollo de la personalidad. Investigaciones acumuladas más

recientes, como la de Lyons-Ruth, en relación al apego, la intersubjetividad y la psicopatología, apoyan esta influencia señalando la respuesta sensible del cuidador como un elemento básico de organización psíquica en el niño.

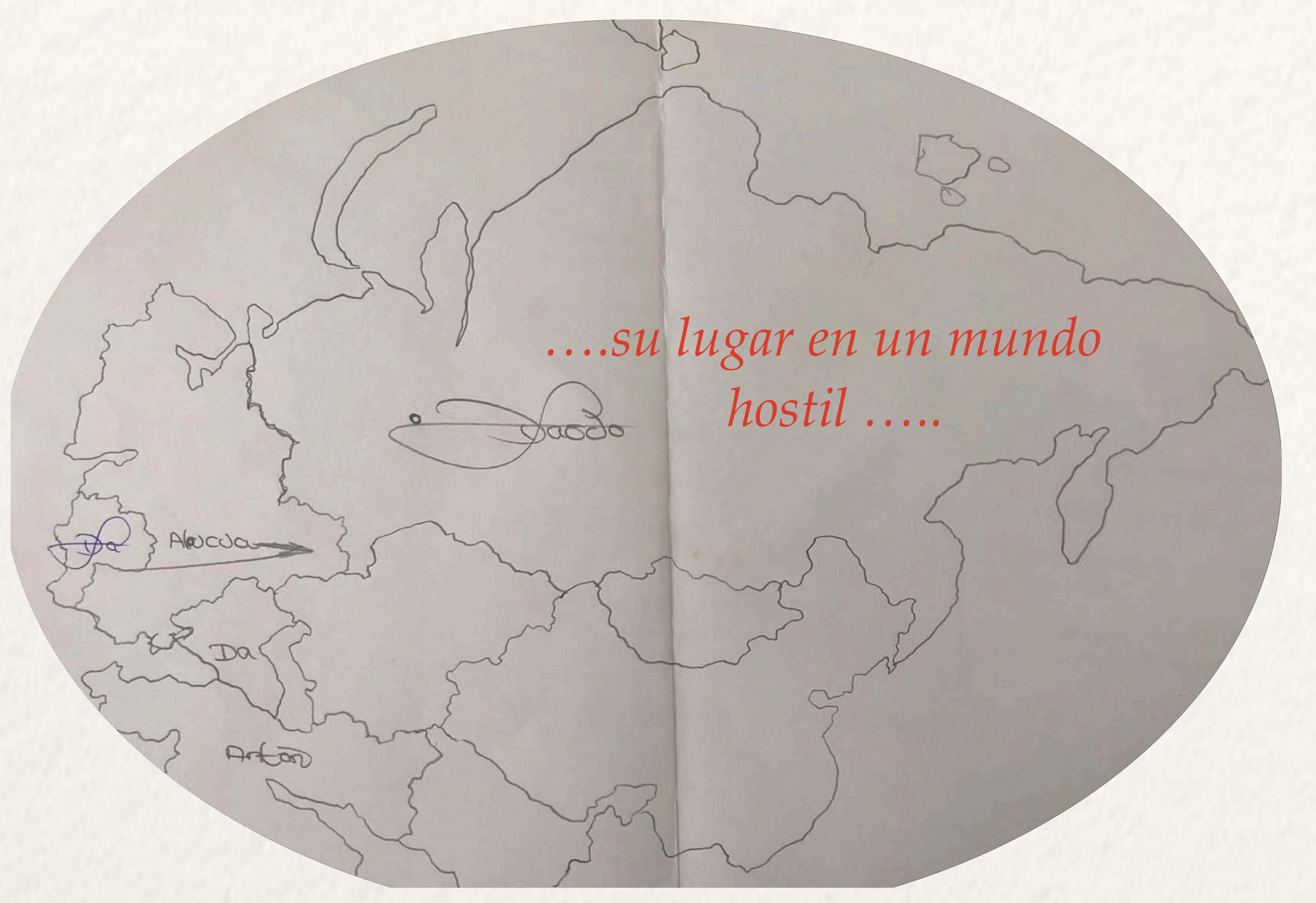

\section{La Mirada Psicoterapéutica}

"Madre heroica" que en el desempeño del rol no puede con todo. Hijo dañado, altamente sensible, frágil, con rechazo al contacto físico, temeroso y a la vez con deseo de encontrar su identidad.

\section{Reflexiones en busca de la Alteridad}

¿Qué hay detrás de este adolescente impulsivo?

¿De qué manera está D., expresando su sufrimiento?

- Si silenciamos sus síntomas... ¿ está perdiendo una oportunidad para ser escuchado?

¿Se puede pensar a D. desde la complejidad social y familiar de su desarrollo y crianza?

¿Acaso no está reflejando esta impulsividad, complejidad personal e interrelacional, ligadas a otras problemáticas?

¿Cómo buscar su identidad, confundido entre la representación de una madre inicial ausente y una madre fusional en segundo encuentro?

¿Qué tipo de apego temprano tuvo a su vez la madre de D.?

¿Con quién se puede identificar si la imagen totalizadora que se le devuelve de sí y que lo unifica es de ser molesto?

¿Cómo atender la demanda reduccionista en la búsqueda de la reevaluación diagnóstica?

Es necesario situarme en su incipiente adolescencia, periodo de grandes transformaciones, desprendimientos, búsqueda de autonomía e independencia. Haciendo frente a un cuerpo que ha sufrido

transformaciones, dejando roles infantiles, enfrentando responsabilidades, buscando a la vez el alejamiento de su madre y su protección.

Se me presenta un reto: sostener una mirada que le ubique como sujeto deseante, con una dura historia, pero también con un futuro abierto.

Necesidad de escucha, comprensión, acompañamiento y contención.

¿Podrá D., desde la creatividad y el arte, desplegar una identidad propia? ¿Podrán madre e hijo generar un espacio de diferenciación mutua?
El Sufrimiento
Daniel (en adelante D.) de 18 años, acude a consulta acompañado por su madre para solicitar un informe de reevaluación de TDAH por intomatología de impulsividad y desatención, de cara a presentarlo en el centro de bachillerato de arte en el que estudia.

D., llega a España con casi 3 años de edad, es de origen ucraniano, allí está internado en condiciones de severa privación nutricional y afectiva. Es doptado en una familia monoparental con crianza de la madre, quien pasa a ser su soporte afectivo y económico principal.

A su llegada presenta raquitismo, retraso en el desarrollo psicomotor y en la adquisición del lenguaje. El único apoyo en el cuidado es el del abuelo aterno, quien fallece cuando D. tenía 8 años. La abuela materna fallece muy joven.

Niño muy deseado y bien acogido, que ha presentado grandes dificultades en ámbito académico y conductual, requiriendo diferentes apoyos profesionales manera intermitente. En tratamiento actual con Risperidona. Último ratamiento psicológico dura 2 años, con un cierre sin despedida por cambio de ciudad del terapeuta.

Cómo se presenta D.?

con sonrisa nerviosa y evitativa, señala sentirse poco reforzado, invalidado re, explotando ante los enfados de esta, cansado, y nervioso. El mundo es una amenaza constante. "nada es permanente", "cada día es un mundo" "hay un gran desequilibrio", "necesidad de tener más hierro duro". Aficionado a la historia en sus conflictos bélicos, a los videojuegos, el dibujo y la fotografía. Poco interesado en las relaciones con iguales.

\section{¿Cómo le ve su madre?}

un niño encantador a su llegada, agotador y difícil en su desarrollo, infantilizado y limitado en el presente.

no se toma las cosas a bien, muestra desconfianza, actúa de forma impulsiva desorganizada, con dificultad para planificar sus deberes, poco constante"

Dibujo de Persona en HTP

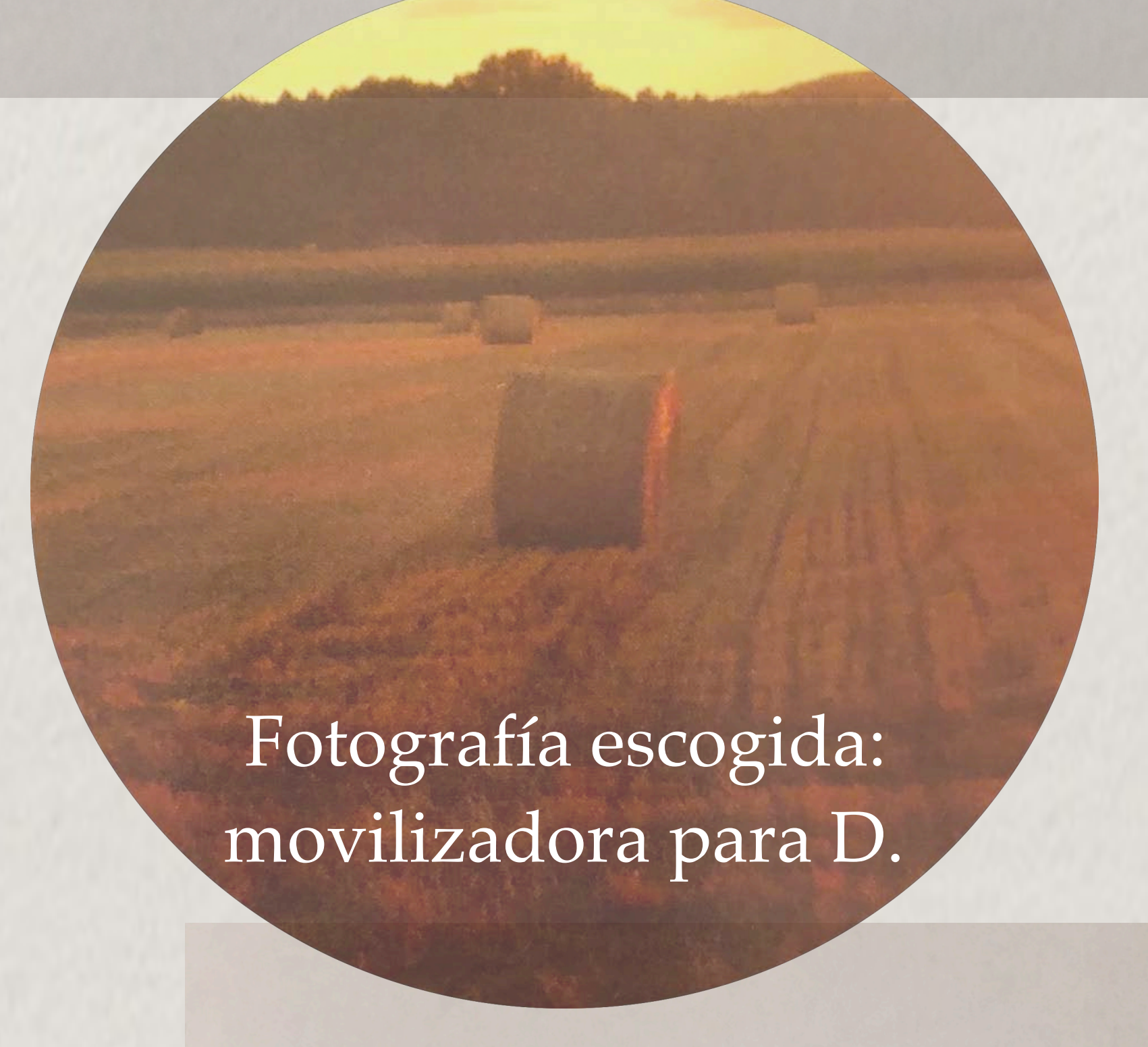

apoyándonos en la fotografía en e trabajo psicoterapéutico....

El entendimiento de este caso hace necesario tomar su singularidad, subjetivar a D., aceptándole con sus diferencias, para comenzar a pensar acerca de las causas que hacen que se presente de este modo.

Entender su impulsividad desde múltiples y complejas causas. Entender su déficit en la estructuración subjetiva, desde la dificultad de organización de su psiquismo en un terreno de conflicto intersubjetivo, con una deprivación muy intensa en el periodo preedípico

Entender su déficit de atención, como una atención errátil, en "alerta" permanente ante un mundo, que percibe, amenazante. Su impulsividad como expresión de la dificultad para inhibir procesos psíquicos primarios, ante una frágil construcción del self, en el que faltó un "otro" para investir el mundo, para libidinizarlo y dotarlo de sentido. 